\title{
Opposite pathobiochemical fate of pyruvate kinase and adenylate kinase in aged rat skeletal muscle as revealed by proteomic DIGE analysis
}

\author{
Philip Doran, Kathleen O'Connell, Joan Gannon, Marcella Kavanagh and Kay Ohlendieck \\ Department of Biology, National University of Ireland, Maynooth, Co. Kildare, Ireland
}

\begin{abstract}
Sarcopenia is the drastic loss of skeletal muscle mass and strength during ageing. In order to better understand the molecular pathogenesis of age-related muscle wasting, we have performed a DIGE analysis of young adult versus old rat skeletal muscle. Proteomic profiling revealed that out of 2493 separated 2-D spots, 69 proteins exhibited a drastically changed expression. Age-dependent alterations in protein abundance indicated dramatic changes in metabolism, contractile activity, myofibrillar remodelling and stress response. In contrast to decreased levels of pyruvate kinase (PK), enolase and phosphofructokinase, the mitochondrial ATP synthase, succinate dehydrogenase, malate dehydrogenase, isocitrate dehydrogenase and adenylate kinase (AK) were increased in senescent fibres. Higher expression levels of myoglobin and fatty acid binding-protein indicated a shift to more aerobic-oxidative metabolism in a slower-twitching aged fibre population. The drastic increase in $\alpha \mathrm{B}$-crystallin and myotilin demonstrated substantial filament remodelling during ageing. An immunoblotting survey of selected muscle proteins confirmed the pathobiochemical transition process in aged muscle metabolism. The proteomic analysis of aged muscle has identified a large cohort of new biomarkers of sarcopenia including opposite changes in PK and AK, which might be useful for the design of improved diagnostic procedures and/or therapeutic strategies to counteract ageing-induced muscle degeneration.
\end{abstract}

\section{Keywords:}

Ageing / DIGE / Fibre transition / Sarcopenia / Skeletal muscle proteomics

\author{
Received: May 16, 2007 \\ Revised: September 27, 2007 \\ Accepted: October 6, 2007
}

\section{Introduction}

Since low skeletal muscle mass in older persons is clearly associated with severe functional impairment and physical disability [1], it is important to elucidate the molecular and cellular mechanisms underlying age-related muscle wasting [2-5]. The biochemical identification of new disease markers

Correspondence: Dr. Kay Ohlendieck, Professor and Chair, Department of Biology, National University of Ireland, Maynooth, Co. Kildare, Ireland

E-mail: kay.ohlendieck@nuim.ie

Fax: +353-(1)-708-3845

Abbreviations: DAPI, diamidino-phenyindole; FABP, fatty acid binding protein; LDH, lactate dehydrogenase; MLC, myosin light chain; PK, pyruvate kinase; SDH, succinate dehydrogenase of sarcopenia may lead to the development of improved diagnostic methods or the design of novel treatment strategies to eliminate the age-induced loss of skeletal muscle fibres [6]. Sarcopenia occurs in all individuals to some degree as a consequence of ageing, but it can be accelerated by a variety of factors including inactivity, poor nutrition and chronic illness [7]. For the investigation of neuromuscular diseases, it is important to take into account that the metabolic and contractile properties of skeletal muscle fibres are dependent on patterns of innervation and activity [8]. Long-term inactivity inevitably results in disuse atrophy triggering a dramatic loss of muscle mass and contractile force. Severe forms of sarcopenia may prevent older individuals from living a normal life and may make them dependent on outside help despite the lack of other medical problems. Large crosssectional studies have attempted to quantify the age-associated decline in skeletal muscle mass [9-11]. Although dif- 
ferent analytical techniques lead to varying results in the extent of the loss of lean muscle mass, the decline in muscle mass appears to be approximately $15-42 \%$ between the ages of 20 and 80 [12]. Importantly, studies that have corrected for the loss in skeletal muscle mass in the age-dependent decline in skeletal muscle strength, suggest that the reduction in the efficiency of muscle strength per muscle mass is even more pronounced [13].

However, conclusions drawn from patient studies into the loss of muscle mass or the decline in muscle strength are complicated by various biomedical factors. Results from the analysis of muscle specimens from younger versus older individuals may be tainted if the general environments, including lifestyle differences, food habits and activity patterns, were fundamentally different for historical reasons [913]. Thus, initial surveys for the biochemical identification of novel biomarkers of age-related muscle wasting should be performed by small-scale animal model proteomics instead of extensive clinical studies [14]. Since human muscle specimens usually exhibit a high degree of interindividual differences [15], it is advantageous to perform comparative investigations with suitable model systems of cellular ageing [14]. Rodent skeletal muscle fibres, especially rat muscle, have been widely accepted as a suitable animal model for studying sarcopenia of old age [16-18]. Besides being essential for identifying new biomarkers, the biochemical characterization of the rat model of sarcopenia is also useful for phenotyping purposes. Once an animal model of a specific neuromuscular disease has been extensively surveyed, this biological knowledge can be exploited in subsequent experimental treatment studies such as gene replacement or stem cell therapy [14]. Differential 2-DE techniques [19] in combination with high-throughput MS analysis [20] suggest themselves for a comprehensive analysis of the aged skeletal muscle proteome [21-24]. Because MS-based proteomics has been widely applied to the cataloguing of skeletal muscle proteins [25-29], the results from new studies on neuromuscular disease processes can be compared to extensive reference maps of the soluble muscle proteome [14]. Fluorescence DIGE analysis represents one of the most advanced biochemical tools for the proteomic profiling of two different sets of protein complements [30], we therefore employed this technique for the identification of new biomarkers of sarcopenia. DIGE greatly reduces gel-to-gel variations [31] and thereby improves the evaluation of trends in changed protein expression patterns [32].

Here, we have used fluorescent tagging of 3-month- versus 30-month-old rat skeletal muscles in order to perform a comprehensive gel electrophoresis-based survey of potential changes in the protein expression pattern between young adult and senescent fibres. The proteomic identification of new biomarkers of sarcopenia may be useful for the interpretation of the results from previous ageing studies [2-5]. The age-related muscle wasting pathology is extremely complex and seems to affect a variety of essential cellular processes, including protection from oxidative stress, main- tenance of mitochondrial metabolism, proper microcirculation, PTMs of key muscle proteins, hormonal balance, ion homeostasis, regenerative potential and excitation-contraction coupling [33-38]. While alterations in certain muscle proteins probably reflect a relatively nonspecific perturbation of cellular metabolism due to fibre atrophy, other abundance changes in key muscle proteins may indicate sarcopeniaspecific modifications. Since the reduction in skeletal muscle mass and decrease in fibre strength has only recently been recognized as a serious health threat for a large portion of society [11], there is an urgent need for establishing proper diagnostic markers for the clinical evaluation of this muscular disorder. Besides individual protein species with a drastically modified density in ageing, also the combination of alterations in several common protein biomarkers would be a potential starting point to develop new diagnostic tools.

Following the densitometric determination of the differential expression pattern for 69 2-D protein spots, PMF analysis identified 18 proteins as being decreased including $\mathrm{PK}$, pyruvate dehydrogenase, myosin binding protein $\mathrm{C}$, carbonic anhydrase, enolase and phosphofructokinase, and 51 proteins being increased such as the mitochondrial ATP synthase, succinate dehydrogenase (SDH), malate dehydrogenase $(\mathrm{MDH})$, isocitrate dehydrogenase (IDH), adenylate kinase (AK), myoglobin, fatty acid binding protein (FABP), $\alpha \mathrm{B}$-crystallin and myotilin. These findings suggest that the biological changes associated with old age include both generally perturbed protein expression pattern and specific alterations in skeletal muscle fibres. With respect to biogerontology and the potential to develop better treatments to counteract sarcopenia, the most significant finding of this study is probably the drastic decrease in PK and concomitant increase in numerous mitochondrial marker enzymes, indicating a shift towards a more aerobic-oxidative metabolism in aged muscle fibres. In addition, the increase in the small heat shock protein $\alpha \mathrm{B}$-crystallin and myotilin suggest substantial remodelling of damaged filamentous elements. The discovery that the enzymes AK and PK experience the opposite pathobiochemical fate during muscle ageing might be exploitable for the future design of a reliable assay to diagnose sarcopenia of old age.

\section{Materials and methods}

\subsection{Materials}

Electrophoresis-grade chemicals, the 2D-Quant kit for determination of protein concentration in electrophoretic samples, the 2D-Clean-Up kit for removal of contaminants prior to IEF, CyDye DIGE fluor minimal dyes Cy2, Cy3 and Cy5, CBB protein dye, IPG strips of $\mathrm{pH}$ 3-10 (linear), IPG buffer of $\mathrm{pH}$ 3-10 for IEF and ACN were purchased from Amersham Biosciences/GE Healthcare (Little Chalfont, Bucks., UK). For microscopy, the DNA-binding dye diamidino-phenyindole (DAPI) and Superfrost Plus positively charged 
microscope slides were obtained from Sigma (Dorset, UK) and Menzel Glässer (Braunschweig, Germany), respectively. Ultrapure protogel acrylamide stock solutions was from National Diagnostics (Atlanta, GA, USA). Sequencing grademodified trypsin for peptide generation was obtained from Promega (Madison, WI, USA). A matrix kit containing CHCA and the external peptide MS calibration kit Peptidemix-1 were from Laserbiolabs (Sophia-Antipolis, France). Immobilon NC nitrocellulose membranes and chemiluminescence substrates were purchased from Pierce and Warriner (Chester, UK) and Millipore (Bedford, MA, USA). Protease inhibitors were from Roche Diagnostics (Mannheim, Germany). Ultrapure lysine for quenching the DIGE labelling reaction, DNase-I enzyme, the presiliconization medium Sigmacote, as well as all other analytical-grade chemicals were purchased from Sigma Chemical Company.

\subsection{Antibodies}

Primary antibodies were obtained from Abcam, Cambridge, UK (ab38237 to PK; ab2101 to lactate dehydrognase; ab36329 to IDH; ab2872 to cardiac FABP), Santa Cruz Biotechnology, Santa Cruz, CA, USA (ab-sc28785 to AK isoform AK1; ab-sc27992 to SDH), Abgent, San Diego, CA, USA (pAb AP7094b to phosphoglycerate kinase 1); Abnova Corporation, Niehu, Taipei, Taiwan (ab2B11-B7 to MDH). Secondary peroxidase-conjugated secondary antibodies were purchased from Chemicon International (Temecula, CA, USA). For confocal laser scanning microscopy, Alexa Fluorconjugated secondary antibodies were obtained from Invitrogen Molecular Probes (Bio Sciences, Dun Laoghaire, Ireland).

\subsection{Animal model of sarcopenia}

Skeletal muscle fibres from 30-month-old Wister rats represent an established animal model of sarcopenia of old age [14]. Since a previous 2-DE analysis of rat muscle using CBB R-250 [23] showed that 7-month-old muscle and 18month-old muscle exhibit more similar protein expression pattern as compared to senescent fibres, the proteomic study outlined here was performed with 3-month-old versus 30-month-old gastrocnemius muscle preparations. For immunoblotting purposes, also 6-month-old muscle samples were used. Freshly dissected muscle specimens from Wistar rats representing young adults versus old animals were obtained from the Bioresource Facility of the Physiology Department, Trinity College Dublin. Rat colonies were kept at a standard light dark cycle and fed at libidum, as previously described [39]. For the optimization of the 2-DE separation of the soluble rat skeletal muscle proteome and the fluorescent DIGE approach, an animal population of 15 young adult and 15 old Wistar rats was used. For individual sets of DIGE analyses, six young samples, six old samples and six pooled standards were prepared for the statistical analysis of the electrophoretically separated rat muscle pro- teome using six DIGE gels [40]. In addition, two pick gels for the MS-based identification of individual 2-D muscle protein spots were used.

\subsection{Preparation of muscle protein extracts}

The preparation, labelling and separation of skeletal muscle proteins was carried out by optimized procedures, as previously described by our laboratory [40-43]. Equal amounts of young adult and senescent gastrocnemius tissue $(\sim 150 \mathrm{mg}$ wet weight) were quick-frozen in liquid nitrogen and ground-up into a fine powder using a mortar and pestle. Following resuspension of the skeletal muscle powder in $1 \mathrm{~mL}$ of lysis buffer (7 M urea, $2 \mathrm{M}$ thiourea, $4 \% \mathrm{w} / \mathrm{v}$ CHAPS, 2\% ampholytes pH 3-10, $100 \mathrm{mM}$ DTT), $2 \mu \mathrm{L}$ of DNase-I (200 units) were added per $100 \mu \mathrm{L}$ of extraction buffer [43]. Otherwise the presence of DNA can lead to excessive viscosity causing problems with the accurate pipetting and transfer of liquid protein aliquotes. In addition, to prevent the proteolytic degradation of sensitive muscle proteins, the extraction medium was supplemented with a previously optimized protease inhibitor cocktail $(0.15 \mu \mathrm{M}$ aprotinin, $0.3 \mu \mathrm{M}$ E-64, $1 \mu \mathrm{M}$ leupetin, $0.2 \mathrm{mM}$ pefabloc, $1.4 \mu \mathrm{M}$ pepstatin, $0.5 \mathrm{mM}$ soybean trypsin inhibitor, $1 \mathrm{mM}$ EDTA) [44]. The subsequent incubation, mixing, centrifugation, ultrasonnication, desalting and rehydration steps were performed by standard methods [41]. Determination of protein concentration and removal of potentially interfering contaminants was carried out with the 2D-Quant kit and 2D-CleanUp kit from Amersham Biosciences/GE Healthcare, respectively. Finally, protein pellets representing young adult and old skeletal muscle protein fractions were resuspended in DIGE lysis buffer (7 M urea, $2 \mathrm{M}$ thiourea, $30 \mathrm{mM}$ Tris, 4\% CHAPS, $\mathrm{pH} 8.5$ ) and adjusted to a protein concentration of $1 \mathrm{mg} / \mathrm{mL}$ [40].

\subsection{DIGE labelling of muscle protein extracts}

For comparative proteomic profiling, $50 \mu \mathrm{g}$ protein aliquotes from young adult, senescent and pooled internal standards were labelled with 200 pmol Cy3 dye, Cy5 dye and Cy2 dye, respectively, for $30 \mathrm{~min}$ on ice and in the dark. As outlined in a recent statistical analysis of the experimental variation of the DIGE technique by Corzett et al. [45], selective labelling artefacts do not appear to play a role in the case of soluble protein species. Therefore, reverse DIGE labelling controls are not routinely employed. In our experience, dye to dye variability is minimal and the findings from expression analyses with different dye combinations do not differ significantly. The dye labelling of skeletal muscle proteins has been previously optimized by our laboratory [40], which included the determination of the most economical protein/ dye ratio. Protein lysates were treated with the 2D-Clean-Up kit from Amersham Biosciences/GE Healthcare prior to the labelling with Cy dyes. Quenching of the fluorescent labelling reaction was carried out with $10 \mathrm{mM}$ lysine for $10 \mathrm{~min}$ 
on ice. Labelled muscle protein extracts were pooled together and gently mixed with an equal volume of $2 \times$ sample buffer (7 M urea, $2 \mathrm{M}$ thiourea, 4\% CHAPS, 2\% IPG Buffer $\mathrm{pH} 3-$ 10,130 mM DTT). The suspension was left on ice for $10 \mathrm{~min}$ and used immediately for 2-DE separation.

\subsection{2-DE separation of muscle extracts}

Standard 2-DE with IEF in the first dimension and SDSPAGE in the second dimension was employed to separate the differentially labelled muscle protein fractions [43]. A reswelling tray from Amersham Biosciences/GE Healthcare was used to rehydrate IPG strips pH 3-10 (linear) for $12 \mathrm{~h}$ with $0.45 \mathrm{~mL}$ of rehydration buffer $(7 \mathrm{M}$ urea, $2 \mathrm{M}$ thiourea, $4 \% \mathrm{w} / \mathrm{v}$ CHAPS, $30 \mathrm{mM}$ Tris, $\mathrm{pH} 8.5$ ) containing $0.05 \%$ bromophenol blue. IEF strips were run on an IPGphor IEF system from Amersham Biosciences/GE Healthcare for a total of $66500 \mathrm{~V} \cdot \mathrm{h}$ [40]. After equilibration, an Ettan DaltTwelve system (Amersham Biosciences/GE Healthcare) with $12.5 \%$ resolving gels was used for the second-dimensional separation of fluorescently labelled skeletal muscle proteins [43]. Following electrophoretic separation at $0.2 \mathrm{~W} /$ gel for $1 \mathrm{~h}$ and at $0.4 \mathrm{~W} /$ gel for $1 \mathrm{~h}$, gels were ran at $1.5 \mathrm{~W} /$ gel overnight. Next morning, slab gel electrophoresis was terminated when the tracking dye had just run off the lower edge of the gel.

\subsection{Protein expression analysis}

A Typhoon Trio variable mode imager system from Amersham Biosciences/GE Healthcare was used to visualize fluorescently labelled proteins. 2-D images from the Cy2-, Cy3and Cy5-labelled protein fractions were scanned using a 488, 532 and $633 \mathrm{~nm}$ laser, respectively [40]. Scanning was performed at $100 \mu \mathrm{m}$ resolution and PMT values for scanned images was between 500 and $560 \mathrm{~V}$. Gel images were cropped using the ImageQuant TL software programme and gel analysis was carried out with the DeCyder V6.0 2-D analysis software package for DIGE (Amersham Biosciences/GE Healthcare). The DeCyder differential in-gel analysis module was employed for pairwise comparison of each young adult versus old muscle sample to the pooled standard present in each gel and for the calculation of normalized spot volume/ protein abundance. Using the DeCyder Biological Variation Analysis module and Cy3:Cy2 and Cy5:Cy2 ratios for each individual protein, datasets from six DIGE gels were taken to calculate average abundance and paired Student's $t$-test $p$ values for muscle proteins. 2-D spots that exhibited a 1.8-fold or more decrease or increase were then identified by PMF analysis.

\subsection{MS analysis}

2-D muscle protein spots of interest, electrophoresed in Coomassie-stained pick gels parallel to DIGE gels, were washed, digested and identified by MALDI-ToF MS analysis as previously optimized by our laboratory [40, 41, 43]. Gel plugs were transferred to $1.5 \mathrm{~mL}$ Eppendorf tubes that had been presiliconized with Sigmacote (Sigma Chemical Company) and were then destained, desalted and washed by standard procedure [40]. Protein digestion was performed for $60 \mathrm{~min}$ at $37^{\circ} \mathrm{C}$ with a buffer containing $1 \mu \mathrm{g}$ of trypsin per $20 \mu \mathrm{L}$ of $50 \mathrm{mM} \mathrm{NH}_{4} \mathrm{HCO}_{3}$. Excess enzyme solution was

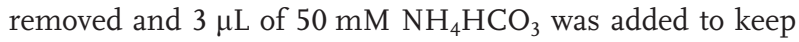
gel pieces wet overnight. Following centrifugation, extraction, concentration and resuspension in $8 \mu \mathrm{L}$ of $3 \% \mathrm{v} / \mathrm{v}$ TFA [43], individual peptide mixtures were stored at $-70^{\circ} \mathrm{C}$ prior to MS analysis. PMF-based identification of muscle proteins by MALDI-ToF MS was carried out with peptide mixtures that had been eluted onto the sample plate with a matrix solution consisting of $5 \mathrm{mg} / \mathrm{mL}$ CHCA in $50 \% \mathrm{v} / \mathrm{v} \mathrm{ACN} /$ $0.1 \% \mathrm{v} / \mathrm{v}$ trifluoroacetic. Mass spectra were recorded with an Ettan MALDI-ToF Pro instrument from Amersham Biosciences, operating in the positive reflector mode at the following parameters: accelerating voltage $20 \mathrm{kV}$; and pulsed extraction: on (focus mass 2500) [40]. For external and internal calibration, Peptidemix-1 from Laserbiolabs containing peaks ranging from 1046.5 to $2465.10 \mathrm{~m} / \mathrm{z}$ and trypsin autolysis peaks at 221.104 and $842.50 \mathrm{~m} / \mathrm{z}$, respectively, were used. Mass spectra were analysed with MALDI evaluation software and skeletal muscle protein species identified via the PMF ProFound search engine. All certainty hits of rat gastrocnemius muscle proteins, generated by the ProFound search engine, were matched against the publicly available search engine MASCOT from Matrixscience.

\subsection{Immunoblotting}

In order to confirm changes in the expression levels of distinct muscle proteins, as revealed by DIGE analysis, 1-D and 2-D immunoblotting with highly specific primary antibodies was employed. Following gel electrophoretic separation, proteins were transferred at $100 \mathrm{~V}$ for $80 \mathrm{~min}$ to Immobilin NC-pure nitrocellulose membranes with the help of a Transblot Cell from BioRad Laboratories (Hemel Hempstead, Herts., UK) [46]. Blots were blocked for $1 \mathrm{~h}$ in $50 \mathrm{mM}$ sodium phosphate, $\mathrm{pH} 7.4,0.9 \% \mathrm{w} / \mathrm{v} \mathrm{NaCl}$, containing $5 \%$ $\mathrm{w} / \mathrm{v}$ fat-free milk powder. NC sheets were then incubated with primary antibodies, washed, exposed to peroxidaseconjugated secondary antibodies and washed again by standard methods [47]. In order to visualize immuno-decorated 2-D muscle protein spots, the SuperSignal ECL kit from Pierce and Warriner was used. A Typhoon Trio variable mode imager from Amersham Biosciences/GE Healthcare with ImageQuant TL software was employed for the densitometric scanning and evaluation of immunoblots.

\subsection{Immunofluorescence microscopy}

Confocal laser scanning microscopy was carried out as previously described in detail [40] using $10 \mu \mathrm{m}$-thick transverse cryosections from young adult versus old gastrocnemius 
muscle. Tissue sections were mounted on Superfrost Plus positively charged microscope slides and then quick-frozen, fixed and blocked by standard methodology [47]. Following incubation overnight at $4{ }^{\circ} \mathrm{C}$ with a primary antibodies, cryosections were carefully washed, and then incubated for $30 \mathrm{~min}$ at $25^{\circ} \mathrm{C}$ with secondary antibodies that had been conjugated to Alexa Fluor 488 dye or Alexa Fluor 594 dye. An Olympus FluoView FV1000 confocal laser scanning microscope (Olympus Life and Material Science Europe, Hamburg, Germany) was employed for image acquisition using the Olympus FluoView Version 1.3c software package. The position of nuclei within muscle fibres was determined by incubation with the DNA-binding dye DAPI [47]. In order to outline the sarcolemma of individual muscle fibres, cryosections were labelled with antibodies to the dystrophin-associated glycoprotein $\beta$-dystroglycan, using Alexa Fluor 594 dye [40]. The labelling of PK was performed with Alexa Fluor dye 488.

\section{Results}

\subsection{DIGE analysis of aged rat skeletal muscle}

In contrast to staining with conventional protein dyes such as $\mathrm{CBB}$ or silver, fluorescent tagging of the entire muscle protein complement drastically increases the number of detectable protein spots in standard 2-DE [20]. A previous proteomic study of muscle ageing in the rat used CBB G-250 as a total protein dye and resulted in the detection of 564 individual 2-D spots [23]. The fluorescent DIGE analysis of aged rat gastrocnemius muscle described here resulted in the visualization of 2493 protein species. Hence, the DIGE-based proteomic profiling study of aged fibres is approximately 4.4fold more sensitive as compared to conventional protein labelling techniques. In addition, gel-to-gel variations in the 2-D protein distribution pattern are greatly reduced due to running the two different proteomes and a pooled standard on the same slab gel [30-32]. Thus, over 7000 differentially labelled muscle proteins can be analysed per gel using DIGE technology, which is far superior to conventional nonfluorescent methods. In order to prevent the introduction of potential artefacts due to subcellular fractionation, this study employed total muscle extracts as starting material for our comparative proteomic profiling exercise. Consequently, the aged skeletal muscle protein complement analysed here represents mostly soluble elements and does therefore not take into account potential changes in integral receptors and other insoluble muscle components. Figure 1 illustrates the representative protein spot pattern in a 2-D gel of Cy2-labelled pooled standards. The overall distribution of abundant 2-D muscle protein spots was shown to be relatively comparable between Cy3-labelled young adult muscle extracts and Cy5-labelled senescent muscle extracts (not shown) and agrees with previously published studies on the skeletal muscle proteome [25-29, 40-43].

\section{DIGE Cy2 master gel of rat gastrocnemius muscle}

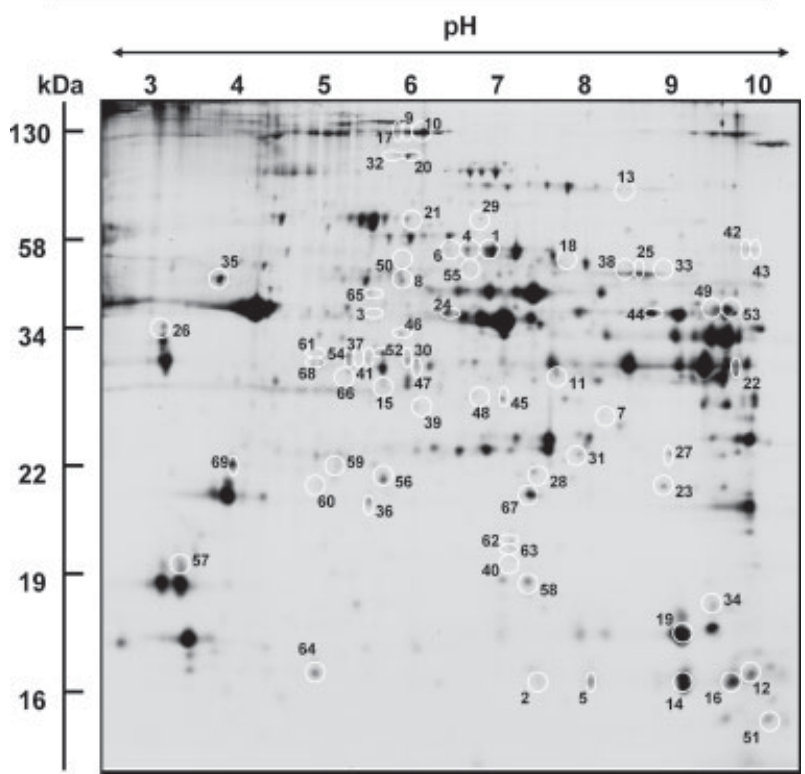

Figure 1. 2-DE analysis of young adult versus senescent skeletal muscle. Shown is a Cy2-labelled master gel of total protein extracts from young adult and senescent skeletal muscle. In this study, the 2-D protein expression pattern of the Cy3-labelled young adult versus the Cy5-labelled aged soluble skeletal muscle proteome was investigated. Proteins with a drastically different expression level are marked by circles and are numbered 1-69. See Table 1 for a detailed listing of skeletal muscle proteins with a changed abundance in aged fibres. The $\mathrm{pH}$ values of the first dimension gel system and molecular mass standards (in $\mathrm{kDa}$ ) of the second dimension are indicated on the top and on the left of the panels, respectively.

\subsection{Proteomic profiling of aged gastrocnemius muscle}

Using a Typhoon Trio variable imager and DeCyder 2-D analysis software, 69 protein species out of 2493 detectable 2-D spots were found to be differentially expressed. Table 1 lists the DIGE-identified proteins that exhibited a drastic change of expression in aged rat gastrocnemius muscle. Muscle proteins with an age-dependent alteration in abundance ranged in molecular mass from apparent 15 to $130 \mathrm{kDa}$ and covered a pI-range from approximately 4 to 9 . A decrease in expression levels was shown for 18 muscle proteins and an increased concentration was observed for 51 proteins in aged muscle preparations. Table 1 lists the percentage sequence coverage achieved by PMF analysis, as well as the relative molecular mass, $\mathrm{pI}$ value, international protein accession number and fold-change of individual muscle proteins affected during ageing. In order to be able to correlate protein spots with an altered density to the list of MS-identified protein species (Table 1), relevant 2-D spots are shown in the DIGE Cy2 master gel of the young adult and senescent skeletal muscle proteome (Fig. 1). The Cy2-labelled gel with the 
Table 1. List of DIGE-identified proteins that exhibit a drastic change of expression in aged rat gastrocnemius muscle

\begin{tabular}{|c|c|c|c|c|c|c|c|}
\hline $\begin{array}{l}\text { Spot } \\
\text { no. }\end{array}$ & Name of identified proteins & $\begin{array}{l}\text { Sequence } \\
\text { coverage }(\%)\end{array}$ & $\begin{array}{l}\text { Molecular } \\
\text { mass (kDa) }\end{array}$ & $\begin{array}{l}\text { Isoelectric } \\
\text { point }(p /)\end{array}$ & $\begin{array}{l}\text { Protein } \\
\text { accession no. }\end{array}$ & $\begin{array}{l}\text { Fold } \\
\text { change }+/-\end{array}$ & $t$-Test \\
\hline 1 & PK & 40.0 & 57.8 & 6.6 & gi| $16757994 \mid$ & -11.21 & $6.2 e-012$ \\
\hline 2 & Unknown protein & - & - & - & - & -6.65 & $8.9 e-016$ \\
\hline 3 & Pyruvate dehydrogenase & 25.9 & 39.3 & 6.2 & gi|50925725| & -5.50 & $1.9 e-006$ \\
\hline 4 & PK & 15.0 & 58.3 & 6.6 & gi|$|16757994|$ & -2.80 & 7.1e-010 \\
\hline 5 & Beta 1 globin & 21.8 & 16.1 & 8.0 & gi $|546056|$ & -2.54 & $5.8 e-012$ \\
\hline 6 & PK & 15.0 & 58.3 & 6.6 & gi| $16757994 \mid$ & -2.43 & $1.4 \mathrm{e}-010$ \\
\hline 7 & Unknown protein & - & - & - & - & -2.15 & $5.7 e-007$ \\
\hline 8 & Enolase & 21.7 & 47.5 & 6.2 & gi|50926833| & -2.14 & $2.6 e-010$ \\
\hline 9 & Myosin binding protein $\mathrm{C}$, fast & 31.2 & 128.3 & 6.2 & gi $62639660 \mid$ & -2.05 & $6.8 e-008$ \\
\hline 10 & Myosin binding protein $\mathrm{C}$, fast & 31.2 & 128.3 & 6.2 & gi|62639660| & -2.05 & $5.6 e-009$ \\
\hline 11 & Carbonic anhydrase CAIII & 15.4 & 29.7 & 6.9 & gi $|31377484|$ & -2.04 & $3.9 e-009$ \\
\hline 12 & Beta 2 globin & 37.7 & 16.0 & 8.9 & gi|8048915| & -2.00 & $1.0 e-009$ \\
\hline 13 & Phosphofructokinase & 12.3 & 86.4 & 8.7 & gi $13929002 \mid$ & -2.00 & 0.00025 \\
\hline 14 & Beta 2 globin & 59.2 & 16.0 & 8.0 & gi|984679| & -2.00 & $2.0 e-011$ \\
\hline 15 & Unknown protein & - & - & - & - & -1.95 & $5.8 e-010$ \\
\hline 16 & Beta 1 globin & 22.0 & 16.0 & 8.2 & gi $|546056|$ & -1.93 & $2.2 e-009$ \\
\hline 17 & Myosin binding protein $\mathrm{C}$, fast & 31.2 & 128.3 & 6.2 & gi $62639660 \mid$ & -1.91 & $5.5 e-007$ \\
\hline 18 & Unknown protein & - & - & - & - & -1.91 & $2.4 \mathrm{e}-006$ \\
\hline 19 & Myoglobin & 26.6 & 17.2 & 7.8 & gi $|11024650|$ & +1.91 & $1.1 e-006$ \\
\hline 20 & Oxoglutarate dehydrogenase & 10.0 & 117.5 & 6.3 & gi $|53734284|$ & +1.91 & $2.9 e-011$ \\
\hline 21 & $\mathrm{SDH}$ & 26.8 & 72.6 & 6.8 & gi $18426858 \mid$ & +1.92 & 4.1e-012 \\
\hline 22 & Troponin T IIla beta & 29.0 & 29.1 & 9.0 & gi $|1256723|$ & +1.92 & $2.7 e-007$ \\
\hline 23 & Phosphoglycerate mutase & 30.0 & 28.7 & 8.9 & gi|8393948| & +1.94 & $1.6 e-010$ \\
\hline 24 & Creatine kinase & 30.0 & 43.2 & 6.6 & gi $|66920|$ & +1.95 & $3.4 \mathrm{e}-010$ \\
\hline 25 & ATP synthase, $\alpha$-subunit & 33.5 & 59.9 & 9.3 & gi $40538742 \mid$ & +2.00 & $1.2 \mathrm{e}-008$ \\
\hline 26 & $\alpha$-Tropomyosin & 26.8 & 32.8 & 4.7 & gi|92921| & +2.00 & $2.2 e-008$ \\
\hline 27 & Vdac1 protein & 51.2 & 32.1 & 8.5 & gi|38051979| & +2.00 & 4.7e-009 \\
\hline 28 & Aldolase & 38.0 & 39.2 & 8.4 & gi $|113609|$ & +2.00 & $4.4 e-010$ \\
\hline 29 & Phosphoglucomutase & 37.2 & 61.7 & 6.1 & gi $77627971 \mid$ & +2.00 & $8.8 e-011$ \\
\hline 30 & Troponin T, fast & 39.0 & 30.7 & 6.2 & gi $|136385|$ & +2.02 & $6.3 e-007$ \\
\hline 31 & Aldolase & 38.0 & 39.2 & 8.4 & gi $|113609|$ & +2.04 & $4.2 e-011$ \\
\hline 32 & Oxoglutarate dehydrogenase & 26.6 & 72.6 & 6.8 & gi $53734284 \mid$ & +2.04 & $3.1 e-011$ \\
\hline 33 & NADH dehydrogenase & 16.8 & 51.4 & 9.0 & gi $54035438 \mid$ & +2.05 & $3.9 e-009$ \\
\hline 34 & Beta globin & 37.7 & 16.0 & 8.9 & gi $|984679|$ & +2.06 & 0.0027 \\
\hline 35 & ATP synthase, $\beta$-subunit & 20.1 & 51.2 & 4.9 & gi|$|1374715|$ & +2.06 & $5.8 e-010$ \\
\hline 36 & CAP1/DJ-1 protein & 42.9 & 20.2 & 6.3 & gi|3250916| & +2.09 & $1.3 e-011$ \\
\hline 37 & Unknown protein & - & - & - & - & +2.12 & $8.3 e-012$ \\
\hline 38 & ATP synthase, $\alpha$-subunit & 33.5 & 59.9 & 9.3 & gi $|40538742|$ & +2.12 & $3.1 e-006$ \\
\hline 39 & Triosephosphate isomerase & 61.0 & 27.4 & 6.5 & gi $|12621074|$ & +2.12 & $5.5 e-008$ \\
\hline 40 & MLC-2 & 22.9 & 36.5 & 7.0 & gi $|17105364|$ & +2.14 & 0.0028 \\
\hline 41 & Unknown protein & - & - & - & - & +2.17 & $1.8 e-008$ \\
\hline 42 & Myotilin & 11.7 & 55.5 & 9.2 & gi|34879286| & +2.20 & $1.6 e-007$ \\
\hline 43 & Myotilin & 11.7 & 55.5 & 9.2 & gi|34879286 & +2.50 & $5.3 e-008$ \\
\hline 44 & Phosphoglycerate kinase & 49.4 & 44.9 & 8.3 & gi $|582444|$ & +2.50 & $2.9 e-010$ \\
\hline 45 & Triosephosphate isomerase & 68.5 & 24.2 & 7.1 & gi $|12621074|$ & +2.50 & $4.9 e-015$ \\
\hline 46 & $\begin{array}{l}\text { Glycerol-3-phosphate dehydro- } \\
\text { genase }\end{array}$ & 10.0 & 38.1 & 6.2 & gi|57527919| & +2.50 & $2.7 e-006$ \\
\hline 47 & Unknown protein & - & - & - & - & +2.53 & $1.2 \mathrm{e}-006$ \\
\hline 48 & Triosephosphate isomerase & 68.3 & 27.4 & 6.9 & gi $|12621074|$ & +2.55 & $7.8 e-010$ \\
\hline 49 & $\mathrm{IDH}$ & 22.0 & 51.4 & 9.2 & gi|50370082| & +2.59 & $1.6 e-011$ \\
\hline 50 & Tripartite motif protein 50 & 47.6 & 53.8 & 5.9 & gi $62641355 \mid$ & +2.59 & $2.2 \mathrm{e}-008$ \\
\hline 51 & Myoglobin & 47.0 & 18.2 & 7.8 & gi $|11024650|$ & +2.59 & $5.0 e-008$ \\
\hline 52 & Unknown protein & - & - & - & - & +2.61 & $1.3 e-010$ \\
\hline 53 & $\mathrm{IDH}$ & 22.0 & 51.4 & 9.2 & gi|50370082| & +2.67 & $4.9 e-010$ \\
\hline 54 & Aldehyde reductase & 20.6 & 36.2 & 6.3 & gi|6978491| & +2.99 & $3.0 \mathrm{e}-010$ \\
\hline 55 & Unknown protein & - & & & - & +3.05 & $1.9 e-005$ \\
\hline
\end{tabular}


Table 1. Continued

\begin{tabular}{|c|c|c|c|c|c|c|c|}
\hline $\begin{array}{l}\text { Spot } \\
\text { no. }\end{array}$ & Name of identified proteins & $\begin{array}{l}\text { Sequence } \\
\text { coverage }(\%)\end{array}$ & $\begin{array}{l}\text { Molecular } \\
\text { mass (kDa) }\end{array}$ & $\begin{array}{l}\text { Isoelectric } \\
\text { point }(p /)\end{array}$ & $\begin{array}{l}\text { Protein } \\
\text { accession no. }\end{array}$ & $\begin{array}{l}\text { Fold } \\
\text { change }+/-\end{array}$ & $t$-Test \\
\hline 56 & CAP1/DJ-1 protein & 42.9 & 20.2 & 6.3 & gi|3250916| & +3.09 & $4.5 e-009$ \\
\hline 57 & MLC-2, cardiac & 43 & 18.9 & 4.8 & gi $|127167|$ & +3.26 & 0.0088 \\
\hline 58 & Unknown protein & - & - & - & - & +3.37 & $1.2 e-005$ \\
\hline 59 & Heat shock protein Hsp27 & 43.0 & 22.8 & 6.1 & gi $|204665|$ & +3.73 & $7.2 \mathrm{e}-012$ \\
\hline 60 & Unknown protein & - & - & - & - & +3.78 & $2.4 \mathrm{e}-010$ \\
\hline 61 & $\mathrm{MDH}$ & 26.9 & 36.6 & 5.9 & gi|37590235| & +3.83 & $6.3 e-010$ \\
\hline 62 & Unknown protein & - & - & - & - & +4.11 & $3.8 e-005$ \\
\hline 63 & $\alpha \mathrm{B}$ Crystallin & 43.0 & 20.1 & 6.8 & gi $|16905067|$ & +4.31 & $3.1 e-007$ \\
\hline 64 & FABP & 27.6 & 14.8 & 5.9 & gi|30582293| & +4.50 & $1.1 e-010$ \\
\hline 65 & $\alpha$-Actin, cardiac & 20.0 & 42.3 & 5.2 & gi|9885049| & +5.58 & $8.8 e-010$ \\
\hline 66 & Unknown protein & - & - & - & - & +5.90 & $3.2 e-009$ \\
\hline 67 & Adenylate kinase AK1 & 43.3 & 21.6 & 7.7 & gi|23831184| & +6.71 & $1.4 \mathrm{e}-015$ \\
\hline 68 & $\mathrm{LDH}$ & 21.0 & 36.9 & 5.1 & gi|8393706| & +7.26 & $6.0 e-011$ \\
\hline 69 & MLC-3 & 43.0 & 22.3 & 5.0 & gi|6981238| & +10.09 & $1.1 \mathrm{e}-013$ \\
\hline
\end{tabular}

Table shows identification, theoretical molecular mass, theoretical pl, percent sequence coverage, fold-change in expression and $t$-test scores for each of the 69 differentially expressed muscle proteins in young adult versus senescent fibres.

mixed standard has marked and numbered all 69 changed muscle protein spots. The protein species with the highest fold-decrease was identified as PK (spots 1, 4 and 6). Other proteins with a drastic decrease in abundance included pyruvate dehydrogenase (spot 3), enolase (spot 8), haemoglobin subunits (spots 5,12 and 16), myosin binding protein $\mathrm{C}$ (spots 9, 10 and 17), carbonic anhydrase isoform CA3 (spot 11) and phosphofructokinase (spot 13). In stark contrast, the highest fold-change increase was observed for myosin light chain (MLC)-3 (spot 69). The muscle enzymes with the most drastic upregulation in expression levels were AK (spot 67) and lactate dehydrogenase (LDH, spot 68). Other proteins of increased density included cardiac $\alpha$-actin (spot 65), FABP (spot 64), the small heat shock protein $\alpha$ B-crystallin (spot 63), $\mathrm{MDH}$ (spot 61), heat shock protein Hsp27 (spot 59), cardiac MLC-2 (spot 57), CAP1/DJ-1 protein (spots 36 and 56), aldehyde reductase (spot 54), IDH (spots 49 and 53), tripartite motif protein 50 (spot 50), myoglobin (spots 19 and 51), triosephosphate isomerase (spots 39, 45 and 48), glycerol-3phosphate dehydrogenase (spot 46), phosphoglycerate kinase (spot 44), myotilin (spots 42 and 43), MLC-2 (spot 40), ATP synthase (spots 25, 35 and 38), haemoglobin (spot 34), NADH dehydrogenase (spot 33), aldolase (spots 28 and 31), phosphoglucomutase (spot 29), oxoglutarate dehydrogenase (spots 20 and 32), troponin T subunits (spots 22 and 30), Vdac1 protein (spot 27), $\alpha$-tropomyosin (spot 26), creatine kinase (spot 24), phosphoglycerate mutase (spot 23) and SDH (spot 21).

\subsection{Opposite pathobiochemical fate of PK and AK in aged muscle}

The detailed 2-DE analysis of the above-described DIGE analysis of young adult versus old muscle revealed a drastic decrease in the glycolytic marker PK and a concomitant increase in the enzyme AK. Figures 2 and 3 show expanded views of the Cy3-, Cy2- and Cy5-labelled 2-D gels and the comparative graphic presentation of the PK and AK spots, respectively. The three horizontal rows of protein spots in Figs. 2A-C represent isoforms of PK, enolase and creatine kinase. In contrast to the other two enzymes that exhibit only small changes in abundance, the central PK-containing 2-D spot in the top row is drastically reduced (Fig. 2C). This finding is illustrated in the graphic comparison of spot intensity in Figs. 2D-F. The concentration of the key glycolytic enzyme PK, which is involved in the final substrate-level phosphorylation reaction of the oxidoreduction-phosphorylation step of the muscle glycolysis pathway, is substantially lower in Cy5-labelled old muscle samples as compared to Cy3-labelled young adult specimens. The opposite result was shown for the AK1 isoform of AK, an important enzyme of nucleotide metabolism that converts two nucleoside diphosphates into a nucleotide triphosphate and a nucleoside monophosphate. The expanded DIGE gel expression pattern in Figs. 3A-C clearly shows the increased density of the AK1containing spot in old muscle preparations. This result is illustrated in the graphic presentation of 2-D spot intensity in Figs. 3D-F. Senescent skeletal muscle fibres appear to show a clear pattern of decreased and increased enzyme concentrations, whereby the opposite fate of PK and AK is a striking combination of altered expression levels.

\subsection{Immunoblotting survey of biomarkers of muscle ageing}

2-D immunoblotting of selected muscle proteins, which have been implicated by the above-described DIGE analysis to be changed in their expression level during ageing, has been conducted with a library of highly specific antibodies. 

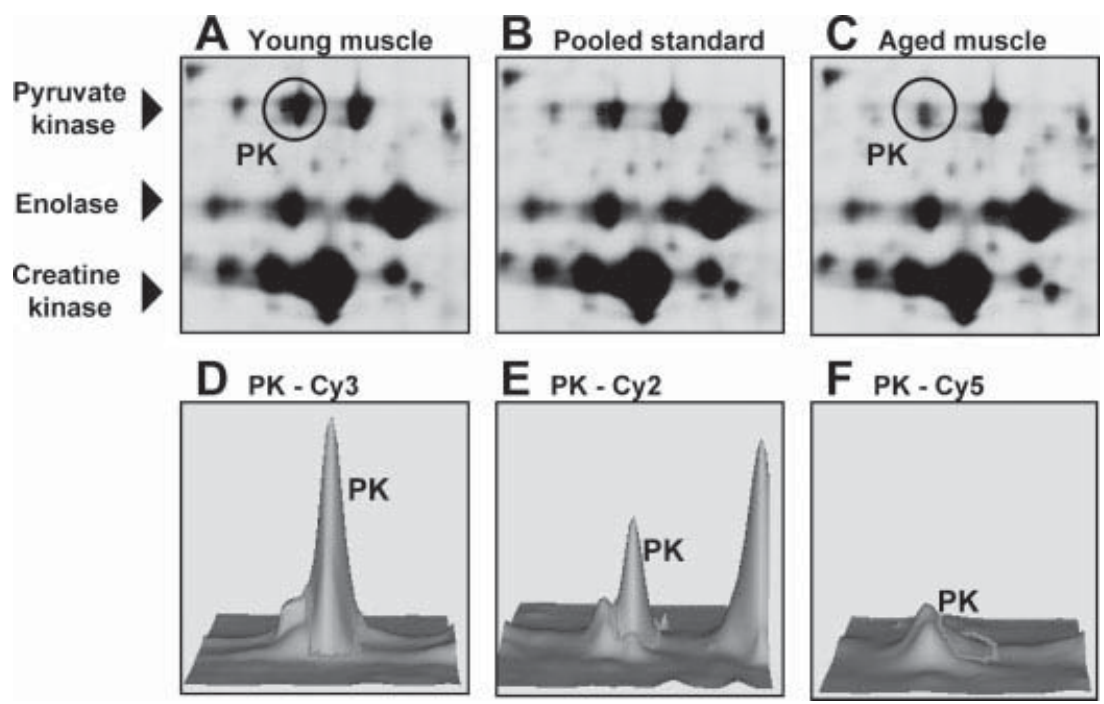

Figure 2. Decreased expression of PK in aged skeletal muscle. Shown is an expanded view of 2-D gels of the Cy3labelled young adult muscle proteome (A), the Cy2-labelled pooled standard (B) and the Cy5-labelled senescent muscle proteome (C), as well as the comparative graphic representation of the PK spot (D-F), which clearly demonstrates the increased expression levels of the enzyme PK in aged fibres. The position of the 2-D spot rows that represent PK, enolase and creatine kinase is indicated by arrowheads on the left. The portion of the 2-D gel (see Fig. 1) shown covers the range of approximately $\mathrm{pH} \mathrm{6-8}$ in the first dimension and a molecular mass range of approximately $30-60 \mathrm{kDa}$ in the second dimension.
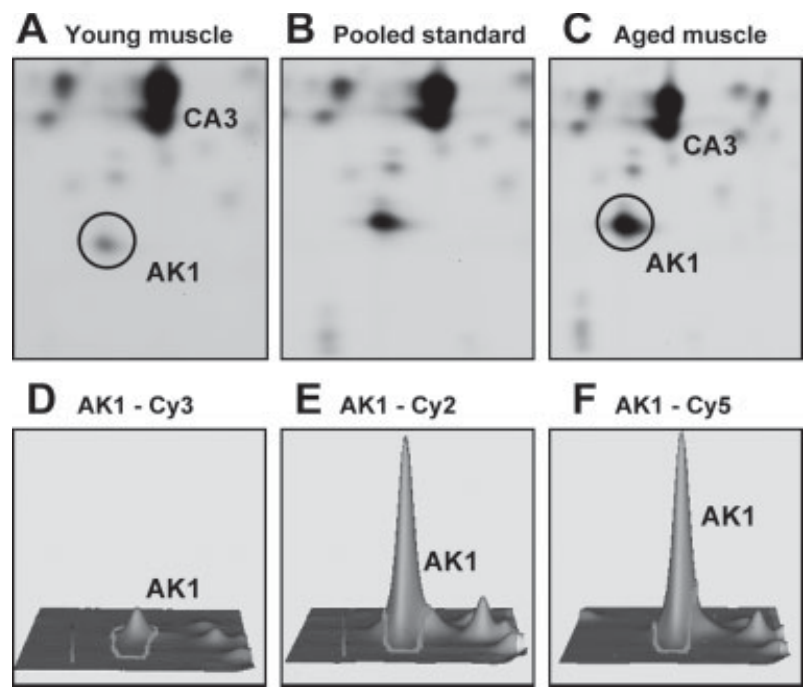

\section{F AK1-Cy5}

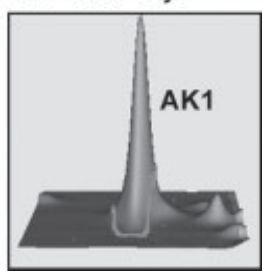

Figure 3. Increased expression of AK in aged skeletal muscle. Shown is an expanded view of 2-D gels of the Cy3-labelled young adult muscle proteome (A), the Cy2-labelled pooled standard (B) and the Cy5-labelled senescent muscle proteome (C), as well as the comparative graphic representation of the AK1 spot (D-F), which clearly demonstrates the decreased expression levels of the enzyme AK in aged fibres. For comparative purposes, the major 2-D spot representing carbonic anhydrase (CA3) is marked. The portion of the 2-D gel (see Fig. 1) shown covers the range of approximately $\mathrm{pH} 7-8$ in the first dimension and a molecular mass range of approximately $20-30 \mathrm{kDa}$ in the second dimension.

Besides 3-month- and 30-month-old specimens, also 6month-old muscle preparations were used for this immunoblot analysis. Therefore, the survey covered the age groups of young adult, adult and senescent fibres. As illustrated in the representative immunoblots of Figs. $4 \mathrm{~A}-\mathrm{R}$, the altered protein expression patterns as determined by DIGE analysis
(Figs. 1-3) were confirmed by antibody labelling of key muscle proteins. The three immuno-decorated protein spots representing PK showed approximately the same modified abundance pattern as the Cy-dye labelled difference gels (Figs. 2A, C). The two more acidic PK-protein species, especially the 2-D spot in the middle, exhibited a drastic agerelated decrease (Figs. 4A-C). The observed higher concentration of the cytosolic marker enzyme LDH in aged muscle was also shown by immunoblot analysis (Figs. 4DF). A shift to more aerobic-oxidative metabolism during ageing was indicated by the increased abundance of the FABP (Figs. 4G-I) and the higher amount of the mitochondrial marker enzymes SDH, IDH and MDH (Figs. 4J-R). Since 2-D labelling of AK resulted in high background staining, 1D immunoblotting was carried out for this key muscle enzyme. Figure 5 confirmed a substantial increase in this enzyme in senescent fibres. While the Coomassie-stained protein pattern showed a relatively comparable overall protein band composition during muscle ageing (Fig. 5A), the immuno-decoration of AK was considerably more intense in 30-month-old fibres, as compared to 3- or 6-month-old specimens (Fig. 5B).

\subsection{Immunofluorescence localization of PK in aged muscle fibres}

Confocal laser scanning microscopy was employed to investigate the subcellular fate of PK in aged muscle fibres. The results from the above-outlined proteomic DIGE analysis and the immunoblot analysis of this enzyme were confirmed by immunofluorescence microscopy. Antigen labelling with Alexa Fluor 488 dye-conjugated secondary antibodies to primary anti-PK antibodies illustrated the decreased cytosolic abundance of PK in aged muscle as compared to young adult fibres (Figs. 6C, F-H). The position of the surface membrane and nuclei was marked by red fluorescence labelling for the 


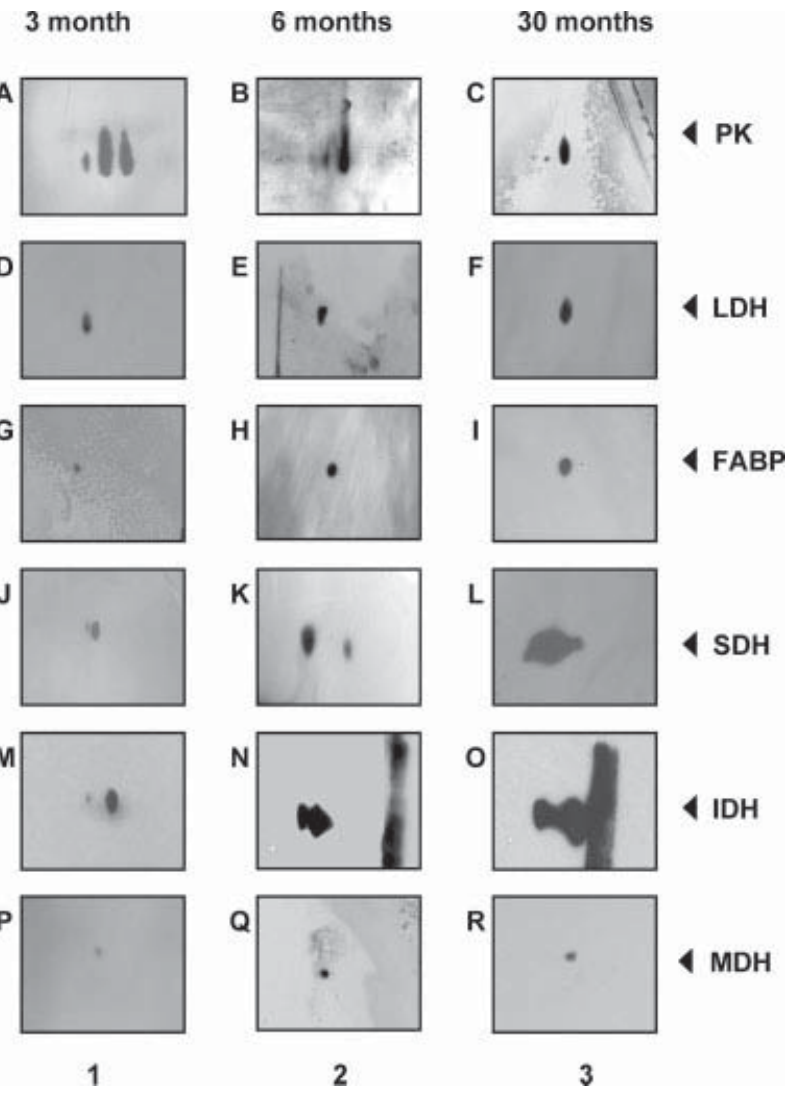

Figure 4. 2-D immunoblotting survey of PK and other key muscle proteins with a differential expression pattern in aged fibres. Shown is an expanded view of immuno-decorated 2-D spots representing PK (A-C), LDH (D-F), FABP (G-I), SDH (J-L), IDH (MO) and $\mathrm{MDH}(\mathrm{P}-\mathrm{R})$. Lanes 1-3 represent total extracts from 3month- (young adult), 6-month- (adult) and 30-month-old (senescent) skeletal muscle fibres, respectively. The position of immuno-decorated spots is marked by arrowheads.

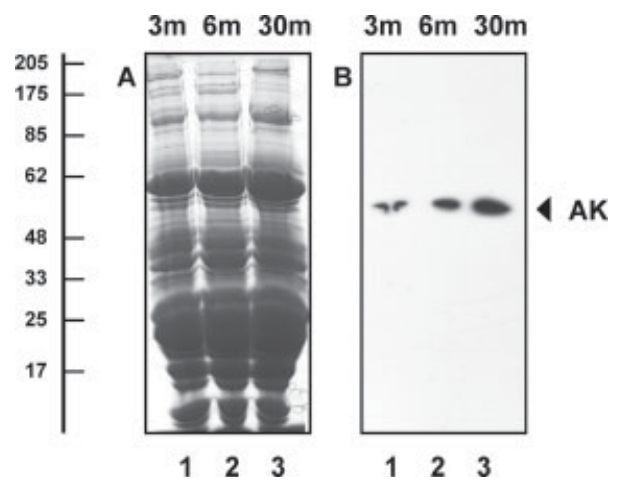

Figure 5. 1-D immunoblot analysis of $A K$ in aged fibres. Shown is a Commassie-stained gel of crude muscle preparations (A) and an NC replica labelled with an antibody to AK (B). Lanes 1-3 represent the electrophoretically separated muscle protein complement from 3-, 6- and 30-month-old rats, respectively. The position of the immuno-decorated AK band is marked by an arrowhead. Molecular mass standards (in $\mathrm{kDa}$ ) are indicated on the left of the panels.
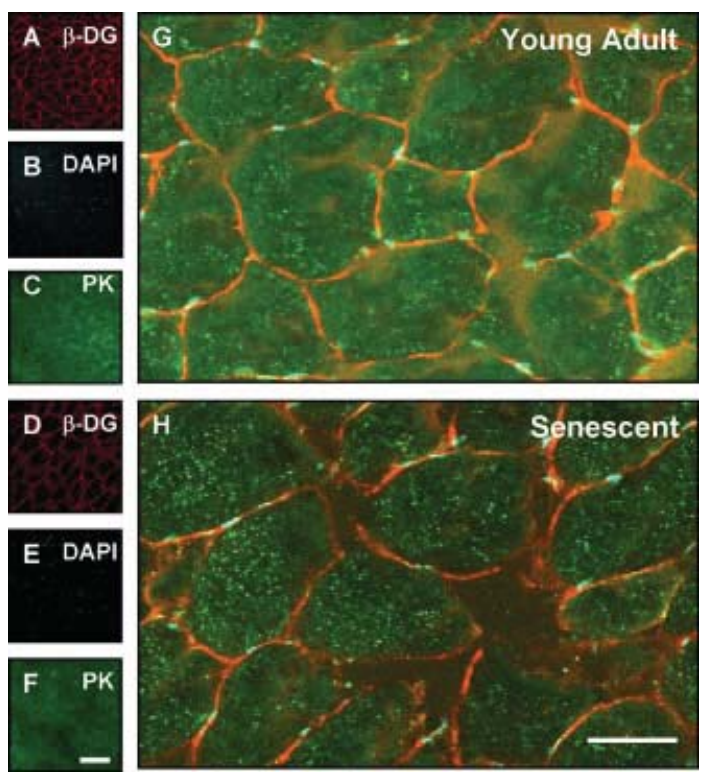

Figure 6. Immunofluorescence localization of PK in aged fibres. Shown is the confocal laser scanning microscopical analysis of 3month-old $(\mathrm{A}-\mathrm{C} ; \mathrm{G})$ versus 30 -month-old $(\mathrm{D}-\mathrm{F} ; \mathrm{H})$ transverse rat muscle cryosections. The sarcolemmal marker $\beta$-dystroglycan ( $\beta$ DG; $A, D, G, H)$ and the enzyme PK $(C, F, G, H)$ were labelled with antibody-conjugated Alexa Fluor 594 dye and Alexa Fluor 488 dye, respectively. The position of nuclei within skeletal muscle fibres was marked by the DNA-binding dye DAPI $(B, E, G, H)$. Panels A-F show individual fluorescence images, while panels $G$ and $\mathrm{H}$ show combined fluorescence images. Bar equals $40 \mu \mathrm{m}$.

sarcolemmal glycoprotein $\beta$-dystroglycan (Figs. 6A, D, G, H) and blue fluorescence labelling with the DNA-binding dye DAPI (Figs. 4B, E, G, H), respectively.

\section{Discussion}

The drastic loss of skeletal muscle mass and strength in old age, now generally referred to as sarcopenia, is a major factor in blocking healthy ageing [6]. However, in both humans and animal models, the capacity to improve skeletal muscle mass and strength with training is preserved [48, 49]. Although a complex relationship exists between sarcopenia, nutrition and other age-induced pathologies [50], it is promising that resistance exercise training can partially reverse muscle weakness in the elderly [51]. One major problem with developing new intervention strategies for sarcopenia is to overcome age-dependent metabolic impairments. Despite the fact that protein-calorie supplements have been shown to be helpful to counteract the loss of skeletal muscle mass [50], elderly patients display a reduced sensitivity towards stimulating protein synthesis from nutritional intake [52]. Thus, physical exercise in combination with nutritional intervention is useful, but on its own is probably not sufficient to treat severe muscle wasting in the aged human. Additional phar- 
macological treatments that interfere with hormonal and metabolic deficiencies might be essential to counteract the overall muscle impairments seen in sarcopenia. In this respect, studying molecular and cellular aspects of the muscle ageing process may help to develop the basis of evidence for decisively improving public health strategies to promote healthy ageing. The systematic cataloguing of sarcopeniaassociated biomarkers is an excellent starting point for the design of more elaborate experimental and clinical studies. In the long-term, proteomic data might be useful for the development of novel therapeutic approaches that prevent or at least minimize age-related impairments and thereby promote improved longevity.

Animal model proteomics is widely employed in the initial identification of novel disease markers [14]. A crucial issue in animal model research is whether a genetically engineered or spontaneous animal strain replicates key pathological features of a human disease process with respect to severity, sequence of symptoms and complexity. An established animal model of sarcopenia is aged rat muscle [16-18], whereby a certain degree of strain-specific differences appears to exist between the main ageing models, e.g. the Fischer F344/N, Fischer F344/NXBN Brown Norway, WI/HicksCar or Wistar rat $[53,54]$. In both, senescent human muscle and aged rodent muscle, the process of fibre regeneration is impaired and seems to play a key role in the loss of muscle mass [55-57]. Although 30-month-old Wistar gastrocnemius muscle is not a perfect replica of all aspects of the human pathology, this animal model exhibits many cellular, histological and functional alterations seen in senescent patients. In the aged rat, fibre numbers, fibre size and fibre type proportions are changed [58, 59] and abnormal cellular features include a higher frequency of longitudinal splitting and fibre degeneration [60]. Impaired contractile properties of both fast and slow muscle relate to the reduced speed of isometric contraction in aged rats [58]. Denervationreinnervation cycles result in the incomplete recruitment of aged fibres [61] and are associated with the loss of whole motor units [59]. A comparative physiological study has shown that aged rat fibres are not able to properly adapt to repetitive mechanical loading [62], making 30-month-old rat muscle a suitable model system to investigate the effect of ageing on skeletal muscle tissue.

This proteomic study of the aged rat muscle model of sarcopenia has discovered a large cohort of new biomarkers of muscle ageing including opposite changes in two key metabolic enzymes, PK and AK. The differential expression of a large number of glycolytic and mitochondrial enzymes such as enolase, aldolase, phosphoglycerate kinase, phosphofructokinase, phosphoglycerate kinase, triosephosphate isomerase, glycerol-3-phosphate dehydrogenase, LDH, ATP synthase, SDH, MDH and IDH in aged muscle are also interesting findings with respect to understanding metabolic changes in senescent fibres [3]. The observed increase in the oxygen-transporter myoglobin and FABP during muscle ageing perfectly agrees with the previously reported shift of older fibre populations to aerobic-oxidative metabolism and slower twitching activity [5]. Upregulation of myotilin and $\alpha \mathrm{B}$-crystallin suggests filament remodelling and autoprotective mechanisms in aged muscle [63]. These detailed proteomic findings, achieved by the application of one of the most sensitive comparative approaches available in modern biochemical analysis, are useful for determining the biological mechanisms involved in ageing and might thus lead to the design of improved diagnostic procedures and/or therapeutic strategies to counteract ageing-induced muscle degeneration.

Oxygen transport and storage plays an essential role in skeletal muscle metabolism. The proteomic profiling of aged muscle suggests a decrease in haemoglobin and an increase in myoglobin. While haemoglobin, which forms in its adult form mostly a $\alpha_{2} \beta_{2}$-configuration, is present in high concentration in erythrocytes, myoglobin is a sarcoplasmic oxygen-carrier that exists as a single polypeptide chain in its functional form [64]. All major haemoglobin spots in the lower right corner of the DIGE master gel showed a decrease, with the exception of one minor 2-D spot, which agrees with a disturbed microcirculation in aged fibres [35]. In contrast, the upregulation of myoglobin supports the idea that aged fibre metabolism shifts to a more aerobic-oxidative mode. While fat and connective tissue increases in the muscle belly of older individuals, muscle fibres of both type I and II are lost during ageing. However, as reviewed by Vandervoort [5], all large-scale histochemical studies have shown a considerably higher loss in type II fibres as compared to type I fibres, agreeing with a slowing of muscle contractile properties in aged muscles. Since denervation and reinnervation processes occur during muscle ageing, a complex pattern of motor unit alterations can be observed in sarcopenia [33].

Since increased levels of mitochondrial fatty acid oxidation in a slower-twitching fibre population would require an altered degree of fuel supply, the increase in the FABP is compatible with the previously described fibre type transformation during ageing [5]. Both, FABP and myoglobin can be considered limiting factors of aerobic-oxidative metabolism in slow-twitch fibres [65] and have previously been shown to increase in abundance during fast-to-slow fibre transition processes [42]. Because aerobic metabolism increases oxygen consumption, which in turn may generate ROS that inhibit enzymes such as oxoglutarate dehydrogenase in skeletal muscle [66], the increased abundance of this mitochondrial enzyme may reflect a compensatory mechanism in aged fibres. Since the CAP1/DJ-1-protein might also be involved in the cellular response to oxidative stress [67], its increase is in line with an increased oxygen supply to the aged fibre population. In contrast to the enhanced sarcoplasmic oxygen-transport system, the $\mathrm{CO}_{2}$-removal mechanism appears to be impaired in sarcopenia. Removal of $\mathrm{CO}_{2}$ is provided by its conversion into carbonic acid by the enzyme carbonic anhydrase [68]. The reduced expression of the muscle-specific isoform CA3 of carbonic anhydrase indicates a reduced availability of this essential hydration reaction and may 
induce pathological levels of $\mathrm{CO}_{2}$ in aged fibres. On the other hand, since the CA3 isoform was shown to be present at a higher density in type I fibres [69], the increased level of this enzyme may simply reflect the age-induced shift to a larger proportion of slow fibres in sarcopenia.

The previously described transition to aerobic-oxidative metabolism in aged fibres with slower contractile properties [5] agrees with the differential expression pattern of many glycolytic and mitochondrial markers in aged muscle. However, the transformation process is more complex as compared to fast-to-slow fibre transitions under conditions of maximum activity $[8,42]$. Besides transdifferentiation due to altered neuromuscular activity patterns, aged muscles also undergo denervation-reinnervation phases triggering fibre atrophy and regeneration cycles with altered motor unit arrangements [37, 70, 71]. This might explain the disturbed expression pattern of myosin, actin, troponin and tropomyosin isoforms, as well as the differential effect on glycolytic enzymes. The glycolytic pathway may be divided in the priming stage, the splitting stage and the oxidoreductionphosphorylation stage of glucose utilization for the production of ATP [72]. The proteomic profile of age-induced changes in muscle metabolism showed a drastic decrease in enolase, phosphofructokinase and PK, but increases in triosephosphate isomerase, aldolase, phosphoglycerate kinase, glycerol-3-phosphate dehydrogenase and LDH. On the other hand, pyruvate dehydrogenase, the enzyme responsible for the conversion of pyruvate to acetyl-CoA during aerobic glycolysis, is decreased. The expression levels of mitochondrial markers of the citric acid cycle, such as MDH, IDH and $\mathrm{SDH}$, were all shown to be elevated. This agrees with a shift to aerobic-oxidative metabolism [5]. The finding that the $\alpha$ and $\beta$-subunits of the mitochondrial ATP synthase are upregulated in aged fibres also suggests an increased level of mitochondria in the overall aged fibre population [36]. The altered expression of AK and creatine kinase in senescent muscle suggests a disturbed nucleotide metabolism in sarcopenia. Since the transfer of energy from high-energy bonds between different metabolites plays a crucial role in skeletal muscle, the increased AK1 levels may represent a compensatory mechanism of aged fibre energy metabolism.

Skeletal muscle degeneration and fibre type shifting causes enormous cellular stress, which usually triggers the increased synthesis of stress elements and chaperones [73]. It is therefore not surprising that the muscle-specific small heat shock proteins Hsp27 and $\alpha \mathrm{B}$-crystallin are up-regulated during the age-induced stress response in skeletal muscle [74]. In addition, important structural elements that control sarcomeric integrity, such as myotilin and myosin binding protein $\mathrm{C}$, are also increased in an age-dependent fashion. Small stress proteins containing a crystallin-domain are mostly involved in filament repair and the prevention of deleterious protein aggregation [75, 76]. Hence, increased levels of $\alpha \mathrm{B}$-crystallin and Hsp27 appear to be an autoprotective mechanism for the rescue of damaged muscle fibres during ageing [74]. Myotilin is a thin filament-associated protein that plays a crucial role in protein complex formation at the Z-disc [77]. Myosin binding protein C supports myosin polymerization in the thick filament [78]. The drastic increase in both sarcomeric support elements seems to be in response to filament restructuring during the ageing process.

In conclusion, the MS-based proteomic screening of aged rat gastrocnemius muscle shown here agrees with previous studies $[23,24]$, supports the idea that sarcopenia is a multifactorial disease [3-6], and has identified several new biomarkers or interesting novel biomarker combinations for the evaluation of sarcopenia of old age. This includes drastic changes in the expression levels of key glycolytic and mitochondrial enzymes, the upregulation of the small stress proteins $\alpha \mathrm{B}$-crystallin and Hsp27, an increase in the sarcomeric elements myotilin and myosin binding protein $\mathrm{C}$, alterations in contractile proteins, and the upregulation of myoglobin and FABP. Based on these proteomic findings, more refined physiological, biochemical and cell biological studies can be designed to further our understanding of the molecular pathogenesis of age-related skeletal muscle wasting.

Research was supported by a principal investigator grant from Science Foundation Ireland (SFI-04/IN3/B614) and equipment grants from the Irish Health Research Board (HRBEQ/2003/3, HRB-EQ/2004/2). The authors thank Dr. Marina Lynch (Trinity College Dublin) for her generous help obtaining aged rat muscle and Dr. Ica Dix (NUI Maynooth) for help with confocal microscopy.

The authors have declared no conflict of interest.

\section{References}

[1] Janssen, I., Heymsfield, S. B., Ross, R., Low relative skeletal muscle mass (sarcopenia) in older persons is associated with functional impairment and physical disability. J. Am. Geriatr. Soc. 2002, 50, 889-896.

[2] Navarro, A., Lopez-Cepero, J. M., Sanchez del Pino, M. J., Skeletal muscle ageing. Front. Biosci. 2001, 6, 26-44.

[3] Carmeli, E., Coleman, R., Reznick, A. Z., The biochemistry of aging muscle. Exp. Gerontol. 2002, 37, 477-489.

[4] Doherty, T. J., Aging and sarcopenia. J. Appl. Physiol. 2003, 95, 1717-1727.

[5] Vandervoort, A. A., Aging of the human neuromuscular system. Muscle Nerve 2002, 25, 17-25.

[6] Greenlund, L. J. S., Nair, K. S., Sarcopenia - consequences, mechanisms, and potential therapies. Mech. Ageing Dev. 2003, 124, 287-299.

[7] Morley, J. E., Baumgartner, R. N., Roubenoff, R., Mayer, J., Nair, K. S., Sarcopenia. J. Lab. Clin. Med. 2001, 137, 231-243.

[8] Fluck, M., Hoppeler, H., Molecular basis of skeletal muscle plasticity-from gene to form and function. Rev. Physiol. Biochem. Pharmacol. 2003, 146, 159-216. 
[9] Forbes, G. B., Reina, J. C., Adult lean body mass declines with age: Some longitudinal observations. Metabolism 1970, 19, 653-663.

[10] Baumgartner, R. N., Stauber, P. M., McHugh, D., Koehler, K. M., Garry, P. J., Cross-sectional age differences in body composition in persons $60+$ years of age. J. Gerontol. A Biol. Sci. Med. Sci. 1995, 50, M307-M316.

[11] Melton, L. J., 3rd, Khosla, S., Crowson, C. S., O'Connor, M. K. et al., Epidemiology of sarcopenia. J. Am. Geriatr. Soc. 2000, 48, 625-630.

[12] Proctor, D. N., O’Brien, P. C., Atkinson, E. J., Nair, K. S., Comparison of techniques to estimate total body skeletal muscle mass in people of different age groups. Am. J. Physiol. 1999, 277, E489-E495.

[13] Lindle, R. S., Metter, E. J., Lynch, N. A., Fleg, J. L. et al., Age and gender comparisons of muscle strength in 654 women and men aged 20-93 yr. J. Appl. Physiol. 1997, 83, 15811587.

[14] Doran, P., Gannon, J., O'Connell, K., Ohlendieck, K., Proteomic profiling of animal models mimicking skeletal muscle disorders. Proteomics Clin. Appl. 2007, 1, 1169-1184.

[15] Ryan, M., Butler-Browne, G., Erzen, I., Mouly, V. et al., Persistent expression of the alpha1S-dihydropyridine receptor in aged human skeletal muscle: Implications for the excitation-contraction uncoupling hypothesis of sarcopenia. Int. J. Mol. Med. 2003, 11, 425-434.

[16] Fernandes, G., Venkatraman, J. T., Turturro, A., Attwood, V. G., Hart, R. W., Effect of food restriction on life span and immune functions in long-lived Fischer-344 x Brown Norway F1 rats. J. Clin. Immunol. 1997, 17, 85-95.

[17] Lingelbach, L. B., McDonald, R. B., Description of the longterm lipogenic effects of dietary carbohydrates in male Fischer 344 rats. J. Nutr. 2000, 130, 3077-3084.

[18] Ryan, M., Carlson, B. M., Ohlendieck, K., Oligomeric status of the dihydropyridine receptor in aged skeletal muscle. Mol. Cell. Biol. Res. Commun. 2001, 4, 224-229.

[19] Wittmann-Liebold, B., Graack, H. R., Pohl, T., Two-dimensional gel electrophoresis as tool for proteomics studies in combination with protein identification by mass spectrometry. Proteomics 2006, 6, 4688-4703.

[20] Doran, P., Donoghue, P., O'Connell, K., Gannon, J., Ohlendieck, K., Proteomic profiling of pathological and aged skeletal muscle fibres by peptide mass fingerprinting. Int. J. Mol. Med. 2007, 19, 547-564.

[21] Kanski, J., Alterman, M. A., Schoneich, C., Proteomic identification of age-dependent protein nitration in rat skeletal muscle. Free Radic. Biol. Med. 2003, 35, 1229-1239.

[22] Kanski, J., Hong, S. J., Schoneich, C., Proteomic analysis of protein nitration in aging skeletal muscle and identification of nitrotyrosine-containing sequences in vivo by nanoelectrospray ionization tandem mass spectrometry. J. Biol. Chem. 2005, 280, 24261-24266.

[23] Piec, I., Listrat, A., Alliot, J., Chambon, C. et al., Differential proteome analysis of aging in rat skeletal muscle. FASEB J. 2005, 19, 1143-1145.

[24] Gelfi, C., Vigano, A., Ripamonti, M., Pontoglio, A. et al., The human muscle proteome in aging. J. Proteome Res. 2006, 5, 1344-1353.
[25] Yan, J. X., Harry, R. A., Wait, R., Welson, S. Y. et al., Separation and identification of rat skeletal muscle proteins using two-dimensional gel electrophoresis and mass spectrometry. Proteomics 2001, 1, 424-434.

[26] Sanchez, J. C., Chiappe, D., Converset, V., Hoogland, C. et al., The mouse SWISS-2D PAGE database: A tool for proteomics study of diabetes and obesity. Proteomics 2001, 1, 136-163.

[27] Gelfi, C., De Palma, S., Cerretelli, P., Begum, S., Wait, R., Two-dimensional protein map of human vastus lateralis muscle. Electrophoresis 2003, 24, 286-295.

[28] Okumura, N., Hashida-Okumura, A., Kita, K., Matsubae, M. et al., Proteomic analysis of slow- and fast-twitch skeletal muscles. Proteomics 2006, 5, 2896-2906.

[29] Gelfi, C., Vigano, A., De Palma, S., Ripamonti, M. et al., 2-D protein maps of rat gastrocnemius and soleus muscles: $A$ tool for muscle plasticity assessment. Proteomics 2006, 6, 321-340.

[30] Unlu, M., Morgan, M. E., Minden, J. S., Difference gel electrophoresis: A single gel method for detecting changes in protein extracts. Electrophoresis 1997, 18, 2071-2077.

[31] Tonge, R., Shaw, J., Middleton, B., Rowlinson, R. et al., Validation and development of fluorescence two-dimensional differential gel electrophoresis proteomics technology. Proteomics 2001, 1, 377-396.

[32] Marouga, R., David, S., Hawkins, E., The development of the DIGE system: 2D fluorescence difference gel analysis technology. Anal. Bioanal. Chem. 2005, 382, 669-678.

[33] Larsson, L., The age-related motor disability: Underlying mechanisms in skeletal muscle at the motor unit, cellular and molecular level. Acta Physiol. Scand. 1998, 163, S27S29.

[34] Squier, T. S., Bigelow, D. J., Protein oxidation and age-dependent alterations in calcium homeostasis. Front. Biosci. 2000, 5, 504-526.

[35] Degens, H., Age-related changes in the microcirculation of skeletal muscle. Adv. Exp. Med. Biol. 1998, 454, 343-348.

[36] Bua, E. A., McKiernan, S. H., Wanagat, J., McKenzie, D., Aiken, J. M., Mitochondrial abnormalities are more frequent in muscles undergoing sarcopenia. J. Appl. Physiol. 2002, 92, 2617-2624.

[37] Renault, V., Thornell, L. E., Eriksson, P. O., Butler-Browne, G., Mouly, V., Regenerative potential of human skeletal muscle during aging. Aging Cell 2002, 1, 132-139.

[38] Ryan, M., Ohlendieck, K., Excitation-contraction uncoupling and sarcopenia. Basic Appl. Myol. 2004, 14, 141-154.

[39] Nolan, Y., Maher, F. O., Martin, D. S., Clarke, R. M. et al., Role of interleukin-4 in regulation of age-related inflammatory changes in the hippocampus. J. Biol. Chem. 2005, 280, 93549362.

[40] Doran, P., Martin, G., Dowling, P., Jockusch, H., Ohlendieck, K., Proteome analysis of the dystrophin-deficient MDX diaphragm reveals a drastic increase in the heat shock protein cvHSP. Proteomics 2006, 6, 4610-4621.

[41] Doran, P., Dowling, P., Lohan, J., McDonnell, K. et al., Subproteomics analysis of $\mathrm{Ca}^{2+}$-binding proteins demonstrates decreased calsequestrin expression in dystrophic mouse skeletal muscle. Eur. J. Biochem. 2004, 271, 3943-3952. 
[42] Donoghue, P., Doran, P., Wynne, K., Pedersen, K. et al., Proteomic profiling of chronic low-frequency stimulated fast muscle. Proteomics 2007, 7, 3417-3430.

[43] Doran, P., Dowling, P., Donoghue, P., Buffini, M., Ohlendieck, K., Reduced expression of regucalcin in young and aged mdx diaphragm indicates abnormal cytosolic calcium handling in dystrophin-deficient muscle. Biochim. Biophys. Acta 2006, 1764, 773-785.

[44] Dowling, P., Doran, P., Ohlendieck, K., Drastic reduction of sarcalumenin in Dp427 (dystrophin of $427 \mathrm{kDa}$ )-deficient fibres indicates that abnormal calcium handling plays a key role in muscular dystrophy. Biochem. J. 2004, 379, 479-488.

[45] Corzett, T. H., Fodor, I. K., Choi, M. W., Walsworth, V. L. et al., Statistical analysis of the experimental variation in the proteomic characterization of human plasma by two-dimensional difference gel electrophoresis. J. Proteome Res. 2006 $5,2611-2619$

[46] Culligan, K., Banville, N., Dowling, P., Ohlendieck, K., Drastic reduction of calsequestrin-like proteins and impaired calcium binding in dystrophic mdx muscle. J. Appl. Physiol. 2002, 92, 435-445.

[47] Dowling, P., Lohan, J., Ohlendieck, K., Comparative analysis of Dp427-deficient mdx tissues shows that the milder dystrophic phenotype of extraocular and toe muscle fibres is associated with a persistent expression of beta-dystroglycan. Eur. J. Cell Biol. 2003, 82, 222-230.

[48] Melov, S., Tarnopolsky, M. A., Beckman, K., Felkey, K., Hubbard, A., Resistance exercise reverses aging in human skeletal muscle. PLoS ONE 2007, 2, e465.

[49] Murlasits, Z., Cutlip, R. G., Geronilla, K. B., Rao, K. M. et al., Resistance training increases heat shock protein levels in skeletal muscle of young and old rats. Exp. Gerontol. 2006, 41, 398-406.

[50] Evans, W. J., Protein nutrition, exercise and aging. J. Am. Coll. Nutr. 2004, 23, 601S-609S.

[51] Galvao, D. A., Taaffe, D. R., Resistance exercise dosage in older adults: Single- versus multiset effects on physical performance and body composition. J. Am. Geriatr. Soc. 2005 53, 2090-2097.

[52] Dela, F., Kjaer, M., Resistance training, insulin sensitivity and muscle function in the elderly. Essays Biochem. 2006, 42 75-88.

[53] Rice, K. M., Lindermann, J. K., Kinnard, R. S., Blough, E. R., The Fischer 344/NNiaHSd X Brown Norway/BiNia is a better model of sarcopenia than the Fischer 344/NNiaHSd: A comparative analysis of muscle mass and contractile properties in aging male rat models. Biogereontology 2005, 6, 335-343.

[54] Eddinger, T. J., Moss, R. L., Cassens, R. G., Fibre number and type composition in extensor digitorum longus, soleus, and diaphragm muscles with aging in Fisher 344 rats. J. His tochem. Cytochem. 1985, 33, 1033-1041.

[55] Conboy, I. M., Rando, T. A., Aging, stem cells and tissue regeneration: Lessons from muscle. Cell Cycle 2005, 4, 407410.

[56] Shi, X., Garry, D. J., Muscle stem cells in development, regeneration, and disease. Genes Dev. 2006, 20, 1692-1708.

[57] Ehrhardt, J., Morgan, J., Regenerative capacity of skeletal muscle. Curr. Opin. Neurol. 2005, 18, 548-553.
[58] Larsson, L., Edstrom, L., Effects of age on enzyme-histochemical fibre spectra and contractile properties of fast- and slow-twitch skeletal muscles in the rat. J. Neurol. Sci. 1986, $76,69-89$.

[59] Edstrom, L., Larsson, L., Effects of age on contractile and enzyme-histochemical properties of fast- and slow-twitch single motor units in the rat. J. Physiol. 1987, 392, 129-145.

[60] Alnaqeeb, M. A., Goldspink, G., Changes in fibre type, number and diameter in developing and ageing skeletal muscle. J. Anat. 1987, 153, 31-45.

[61] Larsson, L., Ansved, T., Edstrom, L., Gorza, L., Schiaffino, S., Effects of age on physiological, immunohistochemical and biochemical properties of fast-twitch single motor units in the rat. J. Physiol. 1991, 443, 257-275.

[62] Cutlip, R. G., Baker, B. A., Geronilla, K. B., Kashon, M. L., Wu, J. Z., The influence of velocity of stretch and dash shortening contractions on muscle performance during chronic exposure: Age effects. Appl. Physiol. Nutr. Metab. 2007, 32, 443-453.

[63] Nicholl, I. D., Quinlan, R. A., Chaperone activity of alphacrystallins modulates intermediate filament assembly EMBO J. 1994, 13, 945-953.

[64] Ordway, G. A., Garry, D. J., Myoglobin: An essential hemoprotein in striated muscle. J. Exp. Biol. 2004, 2007, 34413446 .

[65] Kaufmann, M., Simoneau, J. A., Veerkamp, J. H., Pette, D., Electrostimulation-induced increases in fatty acid-binding protein and myoglobin in rat fast-twitch muscle and comparison with tissue levels in heart. FEBS Lett. 1989, 245, 181184.

[66] Andersson, U., Leighton, B., Young, M. E., Blomstrand, E., Newsholme, E. A., Inactivation of aconitase and oxoglutarate dehydrogenase in skeletal muscle in vitro by superoxide anions and/or nitric oxide. Biochem. Biophys. Res. Commun. 1998, 249, 512-516.

[67] Bonifati, V., Oostra, B. A., Heutink, P., Linking DJ-1 to neurodegeneration offers novel insights for understanding the pathogenesis of Parkinson's disease. J. Mol. Med. 2004, 82, 163-174.

[68] Geers, C., Gros, G., Carbon dioxide transport and carbonic anhydrase in blood and muscle. Physiol. Rev. 2000, 80, 681715.

[69] Cote, C. H., Ambrosio, F., Perreault, G., Metabolic and contractile influence of carbonic anhydrase III in skeletal muscle is age dependent. Am. J. Physiol. 1999, 276, R559-R565.

[70] Luff, A. R., Age-associated changes in the innervation of muscle fibres and changes in the mechanical properties of motor units. Ann. NYAcad. Sci. 1998, 854, 92-101.

[71] Carlson, B. M., Denervation and the aging of skeletal muscle. Basic Appl. Myol. 2004, 14, 135-140.

[72] Erlandsen, H., Abola, E. E., Stevens, R. C., Combining structural genomics and enzymology: Completing the picture in metabolic pathways and enzyme active sites. Curr. Opin. Struct. Biol. 2000, 10, 719-730.

[73] Nishimura, R. N., Sharp, F. R., Heat shock proteins and neuromuscular disease. Muscle Nerve 2005, 32, 693-709.

[74] Doran, P., Gannon, J., O'Connell, K., Ohlendieck, K., Aging skeletal muscle shows a drastic increase in the small heat 
shock proteins $\alpha \mathrm{B}$-crystallin/HspB5 and cvHsp/HspB7. Eur. J. Cell Biol. 2007, 86, 629-640.

[75] de Jong, W. W., Leunissen, J. A., Voorter, C. E., Evolution of the alpha-crystallin/small heat shock protein family. Mol. Biol. Evol. 1993, 10, 103-126.

[76] Neufer, P. D., Ordway, G. A., Williams, R. S., Transient regulation of c-fos, alpha B-crystallin, and hsp70 in muscle during recovery from contractile activity. Am. J. Physiol. 1998, 274, C341-C346.
[77] Mologni, L., Moza, M., Lalowski, M. M., Carpen, O., Characterization of mouse myotilin and its promoter. Biochem. Biophys. Res. Commun. 2005, 329, 1001-1009.

[78] Gautel, M., Furst, D. O., Cocco, A., Schiaffino, S., Isoform transitions of the myosin binding protein $C$ family in developing human and mouse muscles: Lack of isoform transcomplementation in cardiac muscle. Circ. Res. 1998, 82, 124-129. 